Article

\title{
Effect of $\mathrm{LiNO}_{3}$ on Expansion of Alkali-Silica Reaction in Rock Prisms and Concrete Microbars Prepared by Sandstone
}

\author{
Jinxin Liu, Lanqing Yu and Min Deng * \\ College of Materials Science and Engineering, Nanjing Tech University, Nanjing 210009, China; \\ ljx.clnb@njtech.edu.cn (J.L.); yulanqing@njtech.edu.cn (L.Y.) \\ * Correspondence: dengmin@njtech.edu.cn; Tel.: +86-15950591582
}

Received: 19 March 2019; Accepted: 2 April 2019; Published: 9 April 2019

check for updates

\begin{abstract}
The aim of this research is to investigate the effect of $\mathrm{LiNO}_{3}$ on the alkali-silica reaction (ASR) expansion of reactive sandstone and the mechanism through which this occurs. This paper presents the results from tests carried out on rock prisms and concrete microbars prepared by sandstone and $\mathrm{LiNO}_{3}$. The findings show that $\mathrm{LiNO}_{3}$ does not decrease the expansion of these samples unless the molar ratio of $[\mathrm{Li}] /[\mathrm{Na}+\mathrm{K}]$ exceeds 1.66 , and the expansion is greatly increased when its concentration is below this critical concentration. The expansion stress test proves that $\mathrm{Li}_{2} \mathrm{SiO}_{3}$ is obviously expansive. X-ray diffraction (XRD) and scanning electron microscope (SEM) results indicate that $\mathrm{LiNO}_{3}$ reacts with the microcrystalline quartz inside sandstone, inhibiting the formation of ASR gel, and the formation of $\mathrm{Li}_{2} \mathrm{SiO}_{3}$ causes larger expansion. A high concentration of $\mathrm{LiNO}_{3}$ might inhibit the ASR reaction in the early stages, and the formation of $\mathrm{Li}_{2} \mathrm{SiO}_{3}$ causes expansion and cracks in concrete after a long period of time.
\end{abstract}

Keywords: microstructure; deformation; alkali-silica reaction; lithium nitrate

\section{Introduction}

The alkali-silica reaction (ASR) is one of the main reasons for the decline of concrete durability. Following the discovery of the beneficial effects of lithium ions on ASR-related expansion in 1951, the effects of lithium compounds on ASR have been extensively studied [1]. However, the exact role of $\mathrm{Li}+$ ions in controlling ASR is still unclear [2-5]. Several mechanisms have been proposed, including (i) enhance chemical stability of reactive silica exposed to pore solution [6-8], (ii) formation of less expansive Si-Li reaction products [9-12], (iii) formation of physical barrier by insoluble Si-Li reaction products $[11,13,14]$. However, the proposed mechanisms have mainly been determined experimentally under specific conditions and are not applicable to the most situations.

Lithium nitrate $\left(\mathrm{LiNO}_{3}\right)$ is considered to be the most excellent compound for inhibiting ASR in various lithium-containing admixtures. Compared to other lithium-containing admixtures, the major advantage of $\mathrm{LiNO}_{3}$ is that it does not contribute to the increase of hydroxide $\left(\mathrm{OH}^{-}\right)$ion concentration, which eliminates the pessimum effects of other lithium-containing admixtures $[15,16] . \mathrm{LiNO}_{3}$ is also superior to other lithium-containing admixtures due to its neutrality, high solubility and good effect on concrete deformation. The use of $\mathrm{LiNO}_{3}$ as a lithium-containing admixture significantly reduces the expansion and affects the chemical composition and microstructure of the reaction product in mortar samples [11]. The addition of $\mathrm{LiNO}_{3}$ in the molar ratio of [Li]/[Na $\left.+\mathrm{K}\right]$ at a level of 0.74 can generally reduce the expansion of mortar samples prepared with reactive aggregates to reach a safe and nondestructive level [17].

One of the unresolved issues related to the use of lithium-containing admixtures is related to the determination of the reaction product of the aggregate and the solution. Most previous studies 
did not directly confirm the existence of a production layer as a physical barrier, let alone explain the chemical composition, microstructure or effect of protection $[18,19]$. Feng $X[20]$ considered that a mixed product made from the reaction of $\mathrm{LiNO}_{3}$ with aggregate included crystalline $\mathrm{Li}_{2} \mathrm{SiO}_{3}$ crystals and Li-containing low-Ca silica gel, thereby inhibiting the ASR reaction in concrete. Through MR experiments, Kim T [21] showed that the most likely mechanism to explain the excellent ability of $\mathrm{Li}+$ ions to inhibit ASR involves the dense physical barrier, which is formed by the reaction products covers delimited areas on the exposed surface of the reactive aggregate. Zhou BF [22] found that quartz glass slices immersed in the alkaline solution with $\mathrm{LiNO}_{3}$ and $\mathrm{Ca}(\mathrm{OH})_{2}$ were well protected by a production layer consisting of $\mathrm{Li}_{2} \mathrm{SiO}_{3}$ crystals and CSH that densely and firmly covered the surfaces of samples, but seriously corroded in solutions with only $\mathrm{LiNO}_{3}$ or $\mathrm{Ca}(\mathrm{OH})_{2}$.

We studied the expansion of reactive aggregate with the rock prism test and concrete microbar test. $\mathrm{XRD}$ and SEM were used to find the reaction product to explain the effect of $\mathrm{LiNO}_{3}$ on the alkali-silica reaction of the reactive aggregate.

\section{Materials and Methods}

\subsection{Aggregate}

Sandstone aggregate from the Lianghekou hydropower station in China was used. Figure 1 shows the XRD pattern of sandstone. The chemical composition of sandstone is shown in Table 1.

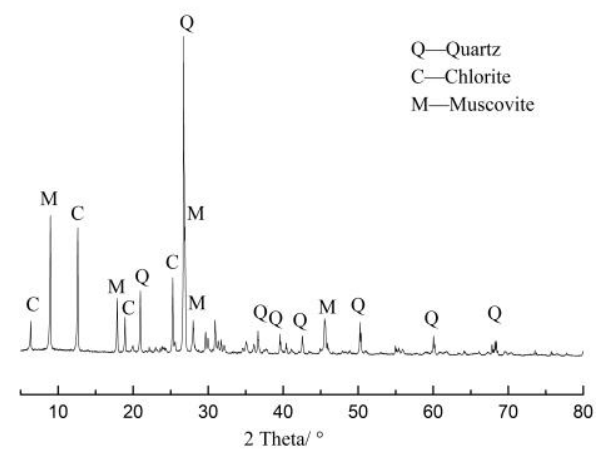

Figure 1. XRD pattern of sandstone.

Table 1. Chemical composition of sandstone.

\begin{tabular}{ccccccccc}
\hline Oxide Component & $\mathrm{SiO}_{2}$ & $\mathrm{Al}_{2} \mathrm{O}_{3}$ & $\mathrm{Fe}_{2} \mathrm{O}_{3}$ & $\mathrm{CaO}$ & $\mathbf{M g O}$ & $\mathrm{K}_{2} \mathrm{O}$ & $\mathrm{Na}_{2} \mathrm{O}$ & LOI. \\
\hline Sandstone $(w \mathrm{w} \%)$ & 53.12 & 17.47 & 5.53 & 5.26 & 3.89 & 4.04 & 0.715 & 9.15 \\
\hline
\end{tabular}

We can see a large amount of microcrystalline quartz in the sandstone from the polarizing microscope photograph Figure 2.

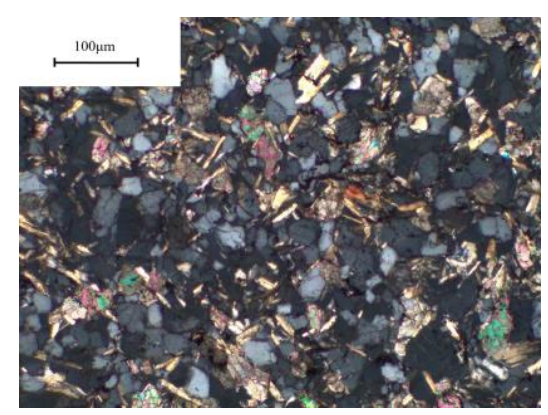

Figure 2. Microstructure of sandstone. 


\subsection{Rock Prism Test}

The effect of $\mathrm{LiNO}_{3}$ on the expansion of sandstone in different alkali solutions was studied in accordance with ASTM C589. The sandstone was cut into the rock prisms $10 \times 10 \times 30 \mathrm{~mm}$ in size in the same direction. The nail heads were fixed on the ends of the rock prisms with P•II525 Portland cement, and the nail heads were covered at both ends with a damp cloth until the cement hardened. The hardened rock column was cured in clear water for $24 \mathrm{~h}$. The length of every rock prism was measured to be the initial length of the rock prism by a spiral micrometer with an accuracy of $0.001 \mathrm{~mm}$. Then the rock prisms were separately cured in different alkaline solutions at $80^{\circ} \mathrm{C}$. The curing solutions were mixed solutions of $\mathrm{NaOH}$ and $\mathrm{LiNO}_{3}$, and the ratios of $\mathrm{Li} / \mathrm{Na}$ were $0,0.41,0.83,1.24,1.66,2$, and 3 respectively. The fresh curing solutions were replaced every 28 days. After curing to the set age, all the rock prisms were taken out and cooled to room temperature. Then, we measured the length and recorded the data to calculate the expansion rate at this time.

\subsection{Concrete Microbar Test}

The concrete microbars of $40 \mathrm{~mm} \times 40 \mathrm{~mm} \times 160 \mathrm{~mm}$ in size had a cement: aggregate ratio of 1 and a water: cement ratio of 0.3 according to RILEM AAR-5. Sandstone aggregates with grain sizes of 5 or $10 \mathrm{~mm}$ were used. The alkali content of cement was adjusted to $2 \% \mathrm{Na}_{2} \mathrm{O}$ equivalent by adding $\mathrm{NaOH}$ into the mixing water. $\mathrm{LiNO}_{3}$ was added to the mixing water in different molar ratios of lithium ions to alkali ions $[\mathrm{Li}] /[\mathrm{Na}+\mathrm{K}]$, such as $0,0.41,0.83,1.24,1.66,2$, and 3 . The fresh curing solutions were replaced every 28 days. $\mathrm{NaOH}$ and $\mathrm{LiNO}_{3}$ were added to the curing solutions in the same molar ratio and the concentration of $\mathrm{NaOH}$ in every solution was $1 \mathrm{~mol} / \mathrm{L}$. After curing to the set age, all concrete microbars were taken out from the curing solutions and cooled to room temperature. Then we measured the length and recorded the data to calculate the expansion rate at this time.

\subsection{Expansion Stress Test Apparatus}

The expansion stress caused by the activity of $\mathrm{SiO}_{2}$ and $\mathrm{LiNO}_{3}$ was tested by the expansion stress test apparatus which can be seen in Figure 3. We put $50 \mathrm{~g} \mathrm{SiO}_{2}$ powder made of quartz glass with granules of less than $80 \mu \mathrm{m}$ in size into the sample mold and compressed it into a compacted body by a press until the body could hold the pressure of $650 \mathrm{MPa}$ for $5 \mathrm{~s}$. Then, we put the mold into the expansion stress test apparatus with a pressure of $25 \pm 0.1 \mathrm{MPa}$ by tightening the nut. The apparatus was cured in a constant temperature curing box in a solution of $1 \mathrm{~mol} / \mathrm{L} \mathrm{NaOH}$ and $0.83 \mathrm{~mol} / \mathrm{L} \mathrm{LiNO}_{3}$ at $60{ }^{\circ} \mathrm{C}$. Because the expansion of the rock prism and the concrete microbar samples greatly increased at an $[\mathrm{Li}] /[\mathrm{Na}+\mathrm{K}]$ dosages of 0.83 compared to the reference sample, the pressure sensor used in this device is suitable for temperature below $70^{\circ} \mathrm{C}$. The expansion stress was calculated according to Equation (1):

$$
\sigma=\frac{4\left(F_{t}-F_{0}\right) g}{\pi d^{2}}
$$

where $\sigma$ is the expansion stress (MPa); $F_{t}$ is the sensor value at time $t(\mathrm{~kg}) ; F_{0}$ is the initial value of the sensor $(\mathrm{kg}) ; g$ is the acceleration due to gravity and with a value of $9.8 \mathrm{~m} / \mathrm{s}^{2} ; d$ is the inner diameter of the mold with a value of $24 \mathrm{~mm}$; and the value of $\pi$ is 3.14 . 


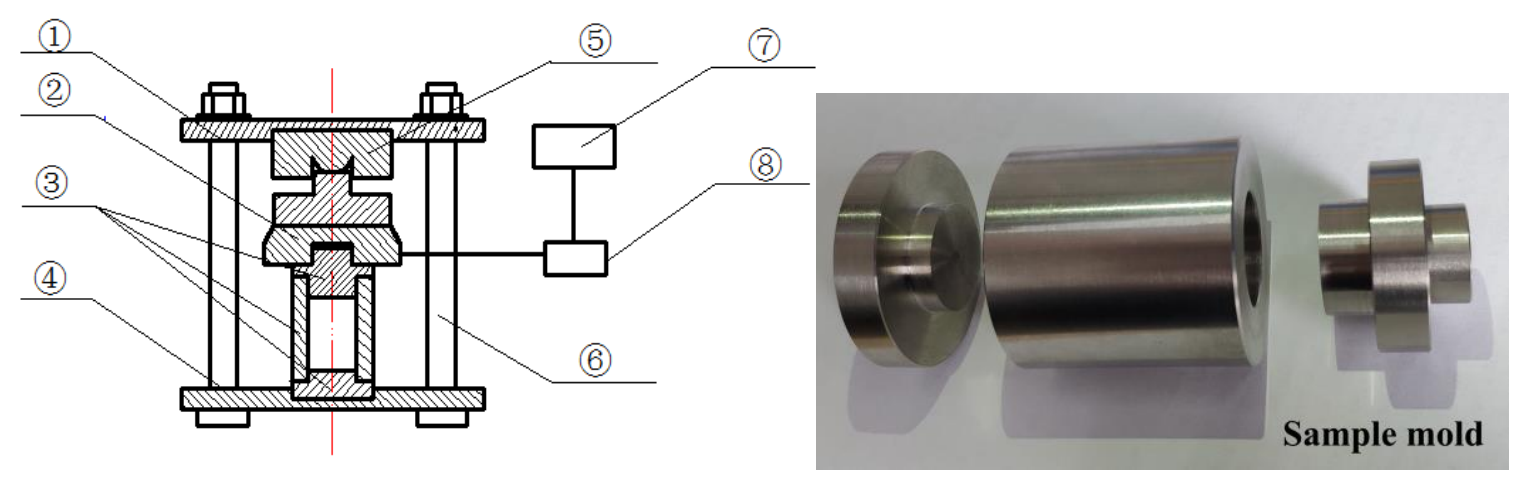

Figure 3. Schematic diagram of the expansion stress testing apparatus (1): top plate; (2): sensor; (3): sample mold; (4): bottom plate; (5): anti-load measuring head; (6): constrained screw; (7): data acquisition system; (8): transmitter).

\section{Results and Discussion}

\subsection{Rock Prism and Concrete Microbar Deformation}

Figure 4 showed the expansion curves of rock prisms cured in solutions with different concentrations of $\mathrm{LiNO}_{3}$ and $1 \mathrm{~mol} / \mathrm{L} \mathrm{NaOH}$ compared to the reference sample cured in $1 \mathrm{~mol} / \mathrm{L}$ $\mathrm{NaOH}$ solution without lithium additive. $\mathrm{LiNO}_{3}$ added at $\mathrm{Li} / \mathrm{Na}$ ratios of $0.41,0.83$, and 1.24 to solutions increased the expansion of samples obviously; the largest expansion was $8.8 \%$, which caused damage to the samples. $\mathrm{LiNO}_{3}$ added at doses of 2 and 3 decreased the expansion of samples; samples expanded by about $0.25 \%$ in comparison to $0.91 \%$ in reference samples at 210 days. A dose of 1.66 decreased expansion after 150 days.

The results indicated that $\mathrm{LiNO}_{3}$ did not decrease the expansion of rock prisms until its concentration exceeded $1.66 \mathrm{~mol} / \mathrm{L}$ and the expansion was greatly increased when its concentration was below this critical concentration. The expansion must be caused by the formation of other reaction products such as $\mathrm{Li}_{2} \mathrm{SiO}_{3}$ rather than just ASR. The data from the early days showed that the lower the $\mathrm{Li}$ concentration was, the faster the reaction was. The expansion curve of the sample at a dose of 0.41 tended to be gentle after 120 days indicating that the main reaction of the expansion had been completed or the expansion stress had been released from the cracks.

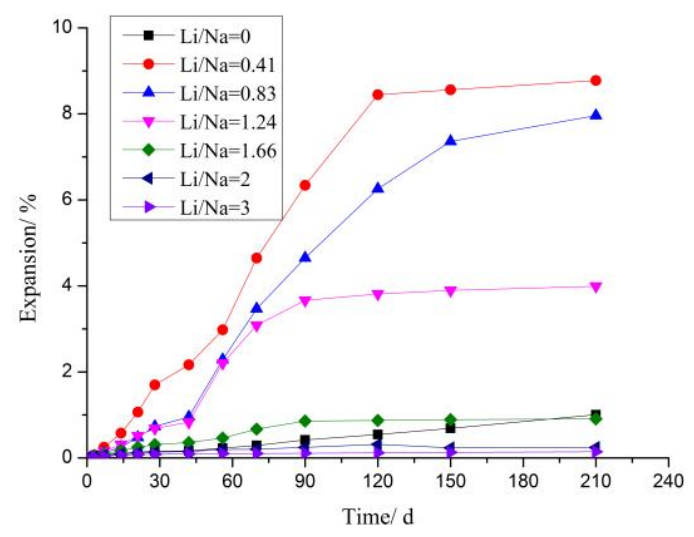

Figure 4. Expansion curves of rock prisms cured in different alkaline solutions at $80^{\circ} \mathrm{C}$.

The rock prisms with large expansion at 210 days cracked or were even damaged, showing that the expansion of aggregate contributed greatly to the expansion of concrete made of sandstone. However, we studied the effect of $\mathrm{LiNO}_{3}$ on concrete microbars using the modified RILEM AAR-5 standard considering the directionality of rock expansion and the limitations of cement on aggregates. 
Figure 5 showed the expansion curves of mortar microbars prepared with $\mathrm{LiNO}_{3}$ compared to the reference sample prepared without lithium additive. The results indicated that critical Li concentration for concrete microbars was dose of 2 . The samples with $\mathrm{LiNO}_{3}$ at $[\mathrm{Li}] /[\mathrm{Na}+\mathrm{K}]$ ratios of 0.41 and 0.83 increased expansion while samples at doses of 1.66, 2, and 3 decreased expansion in comparison to the reference samples. Doses of 1.66, 2, and 3 appeared to be effective in minimizing expansion over the time period tested and even made the samples micro-shrink so the expansion value of samples decreased from about $0.049 \%$ at 63 days to about $0.017 \%$ at 210 days, whereas at a dose of 0.83 , expansion significantly increased after 60 days, and samples were damaged at 120 days. It was hard to make such a huge expansion with ASR gel, and we did not find ASR gel in the samples with $\mathrm{LiNO}_{3}$. So, the reason for expansion must be a different reaction from that of the general ASR.

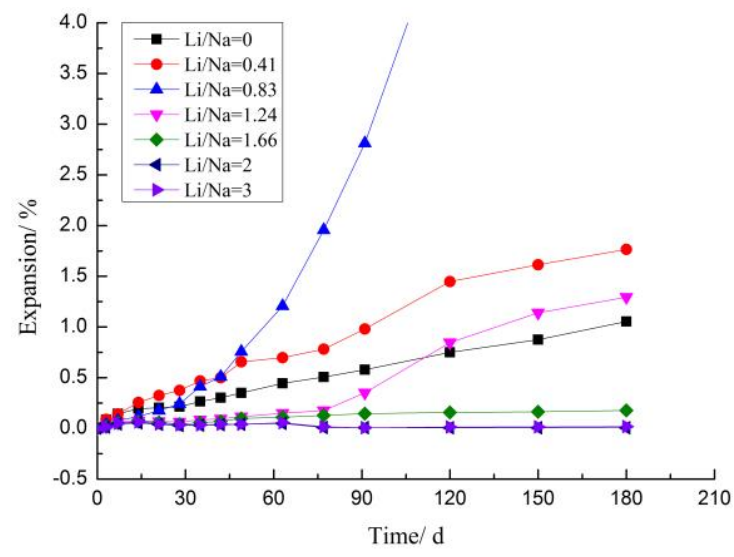

Figure 5. Expansion curves of concrete microbars cured in different alkaline solutions at $80^{\circ} \mathrm{C}$.

At a dosage of 0.41 , expansion showed an increasing trend with respect to the reference sample during the first $28 \mathrm{~d}$ which indicated that the lower the concentration of $\mathrm{Li}^{+}$, the faster the reaction in the early stage. However, dose of 0.83 exhibited the larger expansion compared to dose of 0.41 after 47 days because large number of formed cracks increased the reaction area and dose of 0.83 provided more $\mathrm{Li}^{+}$.

The concentration of $\mathrm{Li}^{+}$can be considered constant as the fresh solutions were replaced every 28 days. The dose of 1.24 appeared to be effective in reducing expansion during the first $80 \mathrm{~d}$, but the expansion increased rapidly after $80 \mathrm{~d}$ and even was greater than the reference samples at $120 \mathrm{~d}$. This phenomenon may result from that the dose of 1.24 was so near the critical concentration that the reactions of increasing expansion occurred so slowly that cracks cannot be observed until samples were cured after several weeks. And with the constantly increasing of cracks, the increasing expansion reaction was more and more intense which led to the accelerated expansion in the later stage. So high concentration of $\mathrm{Li}^{+}$cannot inhibit the expansion of mortar microbars after many years. And this phenomenon also proved that protective layer may not really exist, that is to say, the production layer may not be the real reason for decreasing the expansion of ASR.

By studying the images displayed by the polarizing microscope, we found that the cracks were mainly formed inside the aggregate of the concrete microbars. To study the reaction products in concrete microbars cured in different alkaline solutions, we analyzed the internal aggregate after the reaction at 120 days using XRD. Figure 6 showed the effects of the $\mathrm{LiNO}_{3}$ concentration on the mineralogical composition of crystalline reaction products in concrete microbars cured in $1 \mathrm{~mol} / \mathrm{L}$ $\mathrm{NaOH}$ solution. $\mathrm{Li}_{2} \mathrm{SiO}_{3}$ was the only crystalline compound when the $\mathrm{LiNO}_{3}$ concentration was $0.83 \mathrm{~mol} / \mathrm{L}$. But we did not find any products from XRD when the $\mathrm{LiNO}_{3}$ concentrations were 0 and $2 \mathrm{~mol} / \mathrm{L}$. 


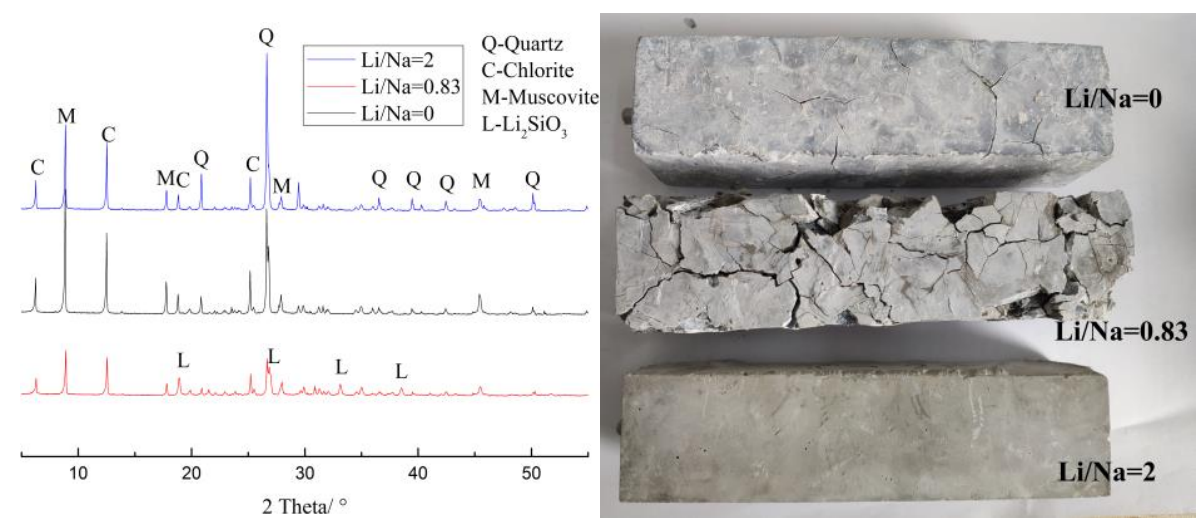

Figure 6. XRD patterns of aggregates in concrete microbars and images of corresponding concrete microbars cured in different alkaline solutions at $80^{\circ} \mathrm{C}$.

This phenomenon was consistent with the results of the macroscopic expansion experiments which showed that the expansion of samples with $0.83 \mathrm{~mol} / \mathrm{L} \mathrm{LiNO}_{3}$ was greater than that of samples with 0 and $2 \mathrm{~mol} / \mathrm{L} \mathrm{LiNO}_{3}$. So, the formation of $\mathrm{Li}_{2} \mathrm{SiO}_{3}$ appeared to be the reason for the expansion. When the $\mathrm{LiNO}_{3}$ concentration was higher than a certain concentration, the product of $\mathrm{Li}_{2} \mathrm{SiO}_{3}$ was greatly reduced but not prohibited, resulting in a sudden increase in expansion at a later stage. When the concentration of $\mathrm{LiNO}_{3}$ was particularly high, the later time might be very long and the products of $\mathrm{Li}_{2} \mathrm{SiO}_{3}$ were very small and difficult to find.

Therefore, we consider $\mathrm{Li}_{2} \mathrm{SiO}_{3}$ to be a deleterious product of the alkali-silica reaction. $\mathrm{LiNO}_{3}$ behaves similarly to other lithium compounds, such as hydroxide or carbonate and gives a pessimum effect.

\subsection{Expansion Stress}

Figure 7 showed that the expansion stress curve of a compacted body which made of $\mathrm{SiO}_{2}$ powder and placed in a self-made stress device. It proved that $\mathrm{Li}_{2} \mathrm{SiO}_{3}$ was obviously expansive. The curing solution included $0.83 \mathrm{~mol} / \mathrm{L} \mathrm{LiNO}_{3}$ and $1 \mathrm{~mol} / \mathrm{L} \mathrm{NaOH}$, and the main reactions occurred as followed:

$$
\begin{gathered}
\mathrm{SiO}_{2}+2 \mathrm{OH}^{-}=\mathrm{H}_{2} \mathrm{O}+\mathrm{SiO}_{3}{ }^{2-} \\
2 \mathrm{Li}^{+}+\mathrm{SiO}_{3}{ }^{2-}=\mathrm{Li}_{2} \mathrm{SiO}_{3} .
\end{gathered}
$$

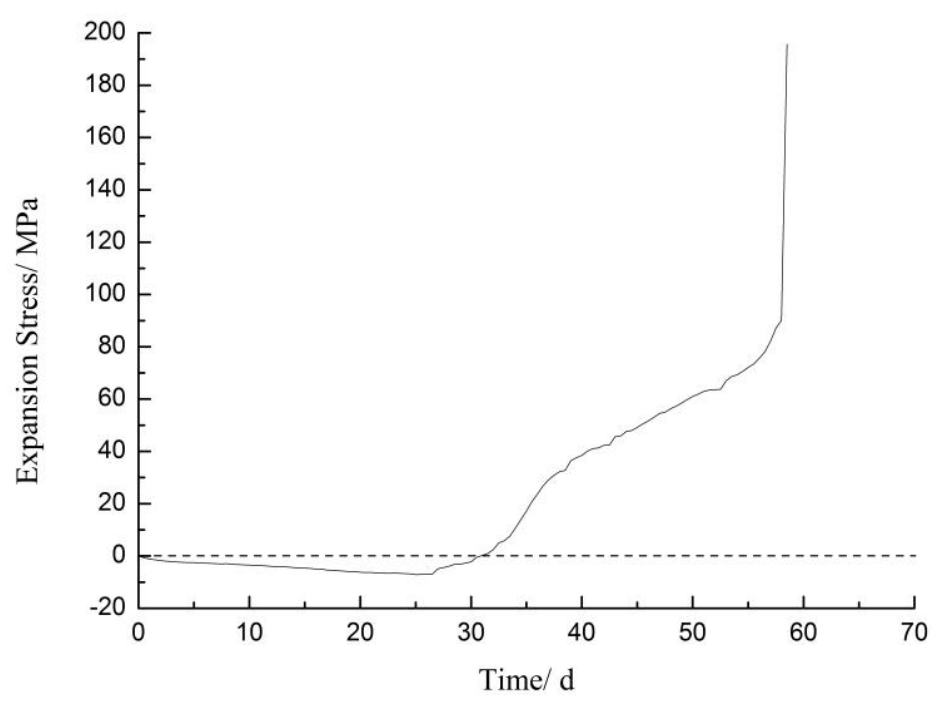

Figure 7. Expansion stress curve of the formed $\mathrm{Li}_{2} \mathrm{SiO}_{3}$. 
The expansion stress was continuously reduced until 27 days, and then it increased until 58 days due to the pre-stressing of the compacted body and the slow penetration of the solution. Finally, the stress broke out, resulting in damage to the device, and stress value was more than $195 \mathrm{MPa}$. The dissolution of $\mathrm{SiO}_{2}$ on the surface of compacted body caused formation of $\mathrm{Li}_{2} \mathrm{SiO}_{3}$, which was difficult for the surface of compacted body to absorb, resulted in a decrease in the expansion stress during the early days. Then, $\mathrm{Li}_{2} \mathrm{SiO}_{3}$ was formed inside, causing a rise in expansion stress as the solution continuously penetrated into the compacted body. The sudden rapid increase in stress on the last day may have been due to the filling of the internal voids of the compacted body and an order of magnitude change in the rate of reaction, which was similar to the rapid expansion of rock prisms and concrete microbars.

\subsection{Microstructure}

Figure 8 presents the findings from the observations of the microstructure of mortar microbars cured in $1 \mathrm{~mol} / \mathrm{L} \mathrm{NaOH}$ with $0.83 \mathrm{~mol} / \mathrm{L} \mathrm{LiNO}_{3}$ at $80{ }^{\circ} \mathrm{C}$. Figure 8 a presented products formed at 42 days. Needle-like and filamentous crystals containing only $\mathrm{Si}$ and $\mathrm{O}$ represent $\mathrm{Li}_{2} \mathrm{SiO}_{3}$ formed on the surface of $\mathrm{SiO}_{2}$ around the cracks, because $\mathrm{Li}$ cannot be detected by energy dispersive spectrometer (EDS). Figure $8 \mathrm{~b}$ presented products at 120 days. The many spindle-like crystals containing only $\mathrm{Si}$ and $\mathrm{O}$ represent $\mathrm{Li}_{2} \mathrm{SiO}_{3}$ which formed by the growth of needle-like and filamentous crystals. There were some $\mathrm{SiO}_{2}$ residues at position 1, 2, and 3, and cracks were mostly filled with products.

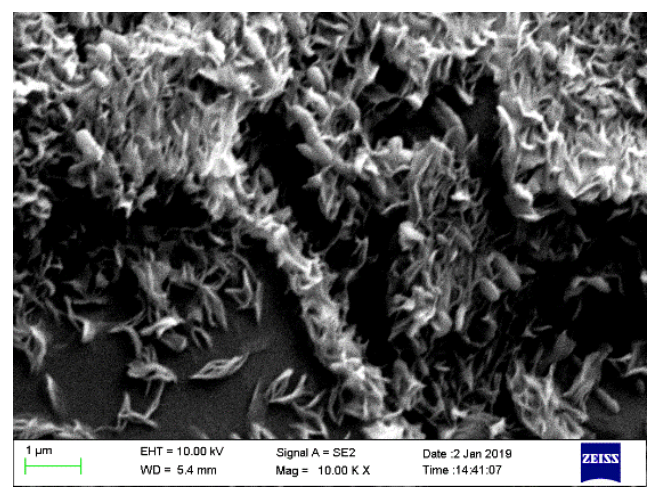

(a)

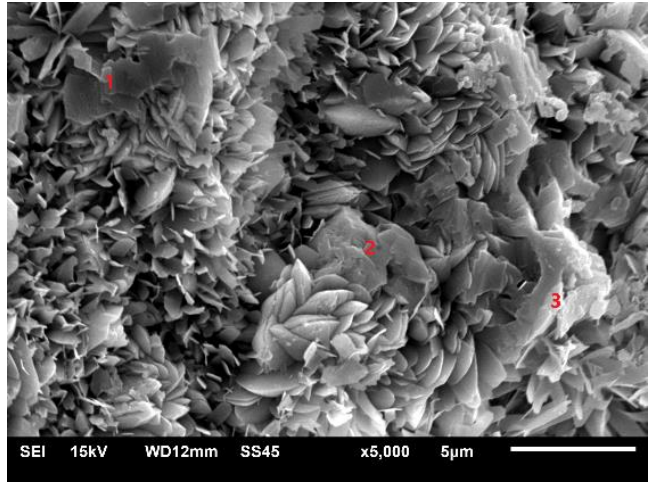

(b)

Figure 8. The SEM images of aggregate in concrete microbars cured in $1 \mathrm{~mol} / \mathrm{L} \mathrm{NaOH}$ with $0.83 \mathrm{~mol} / \mathrm{L}$ $\mathrm{LiNO}_{3}$ at $80{ }^{\circ} \mathrm{C}$ : (a) at 42 days; (b) at 120 days.

As mentioned before, $\mathrm{LiNO}_{3}$ did not decrease the expansion of samples until its concentration exceeded $1.66 \mathrm{~mol} / \mathrm{L}$. The expansion of samples when $\mathrm{LiNO}_{3}$ was present in concentrations below the critical concentration increased more quickly than in the reference sample. There must have been lots of formed products, namely, $\mathrm{Li}_{2} \mathrm{SiO}_{3}$ and ASR gel, leading to significant expansion of mortar microbars. However, it was hard to produce such a huge expansion with ASR gel, and we did not find ASR gel in the samples with $\mathrm{LiNO}_{3}$. It was indicated that $\mathrm{Li}^{+}$reacted with the microcrystalline quartz inside the aggregate causing most of the expansion and this reaction consumed the reactants belonging to the ASR and inhibited the formation of ASR gel. Formed $\mathrm{Li}_{2} \mathrm{SiO}_{3}$ resulted in expansion increasing the reaction area, accelerated the reaction rate and finally formed larger cracks.

Figure 9 presented the findings from the observations of the microstructure of mortar microbars cured in $1 \mathrm{~mol} / \mathrm{L} \mathrm{NaOH}$ with or without $2 \mathrm{~mol} / \mathrm{L} \mathrm{LiNO}_{3}$ at 120 days. Compared with Figure 8, there were little reaction product and cracks in Figure $9 \mathrm{a}$, which shows the sample in solution without $\mathrm{LiNO}_{3}$. The surface shown in Figure $9 \mathrm{~b}$ with $2 \mathrm{~mol} / \mathrm{L} \mathrm{LiNO}_{3}$ was so smooth that there were almost no product formation and no cracks. Excess lithium nitrate made the sandstone denser, which corresponded to the minimal expansion and even micro-shrinkage of concrete microbars. 


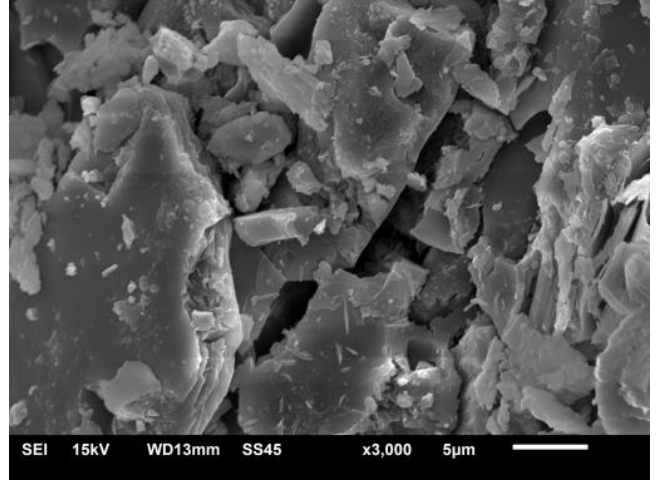

(a)

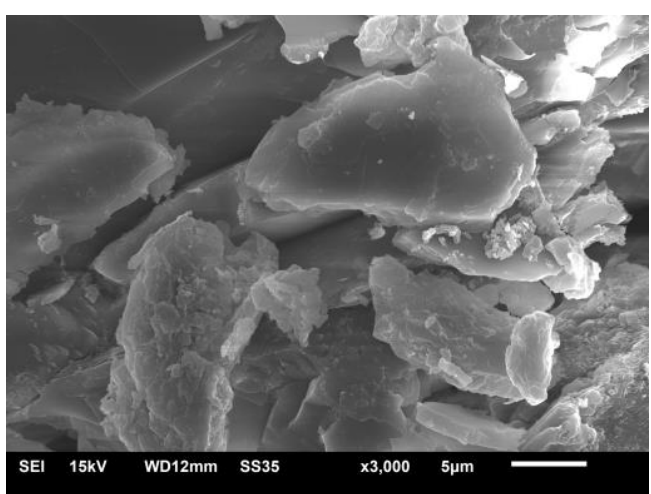

(b)

Figure 9. The SEM images of aggregate in concrete microbars cured in different alkali solutions at $80^{\circ} \mathrm{C}:(\mathbf{a}) 1 \mathrm{~mol} / \mathrm{L} \mathrm{NaOH}$; (b) $1 \mathrm{~mol} / \mathrm{L} \mathrm{NaOH}$ and $2 \mathrm{~mol} / \mathrm{L} \mathrm{LiNO}_{3}$.

However, the mechanism by which $\mathrm{LiNO}_{3}$ control ASR when the concentration was beyond the critical concentration was still unclear, because the reaction product was too difficult to find. However, it is questionable as to whether that less expansive $\mathrm{Si}-\mathrm{Li}$ reaction products formed, because the product of $\mathrm{Li}_{2} \mathrm{SiO}_{3}$ was obviously expansive. Thus, it is worthwhile to continue our research to determine why $\mathrm{Li}_{2} \mathrm{SiO}_{3}$ did not form or formed less in concrete microbars with high concentrations of $\mathrm{LiNO}_{3}$. We believe the discovery of this reason will be of great value for determining the mechanism by which $\mathrm{Li}^{+}$controls ASR.

\section{Conclusions}

1. $\mathrm{LiNO}_{3}$ did not decrease the expansion of rock prisms and concrete microbars with sandstone until the molar ratio of $[\mathrm{Li}] /[\mathrm{Na}+\mathrm{K}]$ exceeded 1.66, and expansion increased when the $\mathrm{LiNO}_{3}$ concentration was below the critical concentration.

2. The expansion stress test proved that $\mathrm{Li}_{2} \mathrm{SiO}_{3}$ is obviously expansive and the expansion stress was more than $195 \mathrm{MPa}$ at the end of the test.

3. The XRD and SEM analyses indicated that product of $\mathrm{Li}_{2} \mathrm{SiO}_{3}$ caused greater expansion of samples, and reaction consumed the reactants belonging to ASR and inhibited the formation of ASR gel. $\mathrm{LiNO}_{3}$ reacted with the microcrystalline quartz inside the aggregate of sandstone and formed $\mathrm{Li}_{2} \mathrm{SiO}_{3}$; the expansion increased the reaction area, accelerated the reaction rate and finally, caused more and larger cracks.

4. The long-term effectiveness of excessive $\mathrm{LiNO}_{3}$ at inhibiting ASR was questionable. The high concentration of $\mathrm{LiNO}_{3}$ only inhibited the ASR reaction in the early stages and the formation of $\mathrm{Li}_{2} \mathrm{SiO}_{3}$ caused expansion and cracks in the concrete after a long period of time.

According to the results, the formation of $\mathrm{Li}_{2} \mathrm{SiO}_{3}$ caused greater expansion of sandstone when in the molar ratio of $[\mathrm{Li}] /[\mathrm{Na}+\mathrm{K}]$ was less than $1.66 . \mathrm{LiSiO}_{3}$ did not form or minimally formed in concrete microbars with higher concentrations of $\mathrm{LiNO}_{3}$, which should be studied further in the future.

Author Contributions: Conceptualization, J.L. and M.D.; methodology, J.L.; software, J.L.; validation, J.L., L.Y., and M.D.; formal analysis, J.L.; investigation, J.L.; resources, J.L., and L.Y.; data curation, J.L.; writing-original draft preparation, J.L.; writing-review and editing, J.L.; visualization, J.L.; supervision, M.D.; project administration, M.D.; funding acquisition, M.D.

Funding: This research was financially supported by the National Key Research and Development Plan of China (2017YFB0309903-01), the Science and Technology Plan Project of Shandong Province Communications (2018B37-02) and the Priority Academic Program Development of Jiangsu Higher Education Institutions (PAPD).

Conflicts of Interest: The authors declare no conflicts of interest. 


\section{References}

1. McCoy, E.J.; Caldwell, A.G. New approach to inhibiting alkali-aggregate expansion. J. Am. Concr. Inst. 1951, 47, 693-706.

2. Islam, M.S.; Ghafoori, N. Experimental study and empirical modeling of lithium nitrate for alkali-silica reactivity. Constr. Build. Mater. 2016, 121,717-726. [CrossRef]

3. Kurtis, K.E.; Monteiro, P. Chemical additives to control expansion of ASR gel: Proposed mechanisms of control. J. Mater. Sci. 2003, 38, 2027-2036. [CrossRef]

4. Ohama, Y.; Demura, K.; Kakegawa, M. Inhibiting ASR with chemical admixtures. In Proceedings of the 8th International Conference Alkali-Aggregate Reaction, Kyoto, Japan, 17-20 July 1989.

5. Tremblay, C.; Bérubé, M.A.; Fournier, B.; Thomas, M.D.A.; Folliard, K.J. Experimental investigation of the mechanisms by which $\mathrm{LiNO}_{3}$ is effective against ASR. Cem. Concr. Res. 2010, 40, 583-597. [CrossRef]

6. Collins, C.L.; Ideker, J.H.; Willis, G.S.; Kurtis, K.E. Examination of the effects of LiOH, LiCl, and $\mathrm{LiNO}_{3}$ on alkali-silica reaction. Cem. Concr. Res. 2004, 34, 1403-1415. [CrossRef]

7. Lawrence, M.; Vivian, H.F. The reactions of various alkalis with silica. Aust. J. Appl. Sci. 1961, 12, 96-103.

8. Wijnen, P.W.J.G.; Beelen, T.P.M.; Haan, J.W.; Rummens, C.P.J.; Ven, L.J.M.; Santen, R.A. Silica gel dissolution in aqueous alkali metal hydroxides studied by 29Si NMR. J. Non Cryst. Solids. 1989, 109, 85-94. [CrossRef]

9. Diamond, S.; Ong, S. The mechanisms of lithium effects on ASR. In Proceedings of the 9th International Conference Alkali-Aggregate Reaction, London, UK, 27-31 July 1992; pp. 269-278.

10. Kawamura, M.; Lwahori, K. ASR gel composition and expansive pressure in mortars under restrain. Cem. Concr. Compos. 2004, 26, 47-56. [CrossRef]

11. Leemann, A.; Lortscher, L.; Bernard, L.; Le Saout, G.; Lothenbach, B.; Espinosa-Marzal, R.M. Mitigation of ASR by the use of $\mathrm{LiNO}_{3}-\mathrm{Characterization}$ of the reaction products. Cem. Concr. Res. 2014, 59, 73-86. [CrossRef]

12. Schneider, J.F.; Hasparyk, N.P.; Silva, D.A.; Monteiro, P.J.M. Effect of lithium nitrate on the alkali-silica reaction gel. J. Am. Ceram. Soc. 2008, 91, 3370-3374. [CrossRef]

13. Feng, X.; Thomas, M.D.A.; Bremner, T.W.; Folliard, K.J.; Fournier, B. New observations on the mechanism of lithium nitrate against alkali silica reaction (ASR). Cem. Concr. Res. 2010, 40, 94-101. [CrossRef]

14. Mitchell, L.D.; Beaudoin, J.J.; Grattan-Bellew, P. The effects of lithium hydroxide solution on alkali silica reaction gels created with opal. Cem. Concr. Res. 2004, 34, 641-649. [CrossRef]

15. Diamond, S. Unique response of $\mathrm{LiNO}_{3}$ as an alkali silica reaction-preventive admixture. Cem. Concr. Res. 1999, 29, 1271-1275. [CrossRef]

16. Stokes, D.B.; Wang, H.H.; Diamond, S. A lithium-based admixture for ASR control that does not increase the pore solution $\mathrm{pH}$. In Proceedings of the 5th CANMET/ACI International Conference on Superplasticizers and Other Chemical Admixtures in Concrete, SP-173, Rome, Italy, 7-10 October 1997; pp. 855-867.

17. Zapała-Sławeta, J.; Owsiak, Z. The role of lithium compounds in mitigating alkali-gravel aggregate reaction. Constr. Build. Mater. 2016, 115, 299-303. [CrossRef]

18. Kawamura, M.; Fuwa, H. Effects of lithium salts on ASR gel composition and expansion of mortars. Cem. Concr. Res. 2003, 33, 913-919. [CrossRef]

19. Berra, M.; Mangialardi, T.; Paolini, A.E. Use of lithium compounds to prevent expansive alkali-silica reactivity in concrete. Adv. Cem. Based. Mater. 2003, 15, 145-154. [CrossRef]

20. Feng, X.; Thomas, M.D.A.; Bremner, T.W.; Folliard, K.J.; Fournier, B. Summary of research on the effect of $\mathrm{LiNO}_{3}$ on alkali-silica reaction in new concrete. Cem. Concr. Res. 2010, 40, 636-642. [CrossRef]

21. Kim, T.; Olek, J. The effects of lithium ions on chemical sequence of alkali-silica reaction. Cem. Concr. Res. 2016, 79, 159-168. [CrossRef]

22. Zhou, B.F.; Mao, Z.Y.; Deng, M. Reaction of Quartz Glass in Lithium-Containing Alkaline Solutions with or without Ca; Royal Society Open Science: London, UK, 2018; Volume 5.

(C) 2019 by the authors. Licensee MDPI, Basel, Switzerland. This article is an open access article distributed under the terms and conditions of the Creative Commons Attribution (CC BY) license (http:/ / creativecommons.org/licenses/by/4.0/). 